\title{
Canker Sore
}

National Cancer Institute

\section{Source}

National Cancer Institute. Canker Sore. NCI Thesaurus. Code C62546.

A recurrent disease of the oral mucosa of unknown etiology. It is characterized by small white ulcerative lesions, single or multiple, round or oval, lasting for 7-14 days and healing without scarring. 